\title{
A Tourists' Travel Intention in the Context of Covid-19 in Viet Nam
}

\author{
Quang - Tien Tran ${ }^{1} \quad$ Thi- Ngọc Mai Nguyen ${ }^{2} \quad$ Anh- Tu Nguyen $^{3} \quad$ Hung - Cuong Nguyen ${ }^{4}$ \\ Manh-Cuong $\mathrm{Vu}^{5^{*}}$ \\ 1.Department of business administration, Viet Nam Women's Academy, Hanoi, Vietnam \\ 2.Hanoi University of Home Affairs, Hanoi City, Vietnam
}

\begin{abstract}
The novel coronavirus pneumonia has seriously affected the development of tourism in Vietnam and even the whole world. Combining the current of VietNam's mitigation and the gradual recovery of tourism, this paper puts the research perspective on tourists' travel intention, and constructs a new theoretical structure by using TPB and TRA theory, This study presents the findings of a research which examined the relationship Subject norms and perceived behavioral control have a significant impact on Attitude and tourists' desire to travel; the Attitude and desire to travel has a significant positive impact on tourists' travel intention, a little empirical study investigates these relationships together. This article investigates these relationships using SEM with data 437 tourists in the Vietnam. Findings of the study revealed that Attitude mediates the relationship between Subject norms, Perceived Behavioral Control, and Travel intention. Desire to travel mediates the relationship between Subject Norm, Perceived Behavioral Control and Travel intention. Based on the study findings, implications for theory and practice are discussed.
\end{abstract}

Keywords: COVID-19, Theory of planned behaviour(TPB), Theory of reasoned action(TRA), Viet Nam

DOI: $10.7176 / \mathrm{EJBM} / 13-14-07$

Publication date:July $31^{\text {st }} 2021$

\section{Introduction}

Because of the prevalence of covid-19, the world is facing an unprecedented global health, social and economic emergency. Tourism is the most affected sector. The COVID-19 is defined by WTO (World Tourism Organization) as "pandemic". According to the data of World Tourism Organization, the number of international tourists will be reduced by $58 \%$ to $78 \%$ in 2020 , international tourists will be reduced by 850 million to 1.1 billion, tourism revenues will be reduced by 860 billion to 1.2 trillion US dollars, and 100 million to 120 million direct tourism jobs are at risk[1]. In the process of tourism recovery, to explore the domestic tourists in Viet Nam intention and the influencing factors of related travel intention is conducive to the relevant management departments to guide and enhance the tourists' travel intention, so as to further accelerate the pace of comprehensive recovery of the tourism Industry

\section{Literature Review and Hypotheses Development}

There are many studies have been used TRA,TPB and show the predictive power of the theory on actual behaviour in different contexts[2]. All these kinds of individual behaviour can account for the theory of reasoned action. It is clear that tourists's intention to perform an actual behaviour is jointly determined by the two factors; Perceived Behavioral Control and subjective norm toward the Desire to travel, attitude. In line with this, many studies have found a positive relationship between tourists's attitude and behavioural intention, [3-6]. In this context, attitude actually related to the behavioural intention as individuals form intentions to perform behaviours toward which they are positively oriented. For instance, this research relates to the tourists's intention, whereby if people have a positive attitude toward services that travel company services, they are more likely to have the intention to use these services. Similarly, thesecond predictor of tourists's intention is the Desire to travel, which is the important referent and his or her want to travel [7]. According to Fishbein and Ajzen (1985), subjective norm is the social pressure from others who are important to an individual on whether or not to engage in a certain behaviour. The rationale for the effect of $\mathrm{SN}$ is that a person may choose to engage certain behaviour, even though it is not a favourable one at first. If their important referents think they should, they will comply with the particular behavior [8]. Several studies have shown a positive relationship between subjective norm and tourist's Attitude, Desire to travel. Besides this studies have show a positive relationship between Perceived Behavioral Control and tourist's Attitude, Desire to travel[9]. In the framework of this study, the researchers investigated these antecedents to examine Travel intention to domestic tourists in the context of Covid-19 in Viet Nam.

\subsection{Subject Norm}

Defines subjective norm as "the inner view about key characters in the decision maker's life, making the decision-maker to aspire to perform (or not act) in a certain way." In the setting of TRA and theory of planned 
behavior, the individual views whether favorable or nonfavorable, either positive or negative, reflects the subjective norm towards the particular behavior [10]. In other words, the norms can identify and formulate rules and regulations for the society and the individuals in the society can follow these taken for granted norms to perform particular behavior [11]. The two components i.e. normative beliefs (like others expect how the individual can perform) and motivation to comply (like positive and negative beliefs Ajzen, (1991) subject norms refer to the social pressure that individuals feel due to the implementation or non-implementation of certain environmental behaviors[10]. According to Moutinho's (1987) research, any individual or organization of a related group may have a key influence on an individual's beliefs, attitudes, and choices, because an individual may observe the views of his/her group [12]. Qiu (2017) based on the TPB expansion model, studied the civilized behavior of Chinese citizens traveling abroad, and the results showed that subject norms have direct and indirect effects on behaviour attitudes and Desire to travel [13]. Based on this, the following assumptions are made:

H1: Subject norms have a positive influence on tourists' attitudes

H2: Subject norms have a positive influence on tourists' desire to travel.

\subsection{Perceived Behavioral Control}

Perceived behavioral control is the perception of the difficulty of behavior execution [10]. Theory of planned behavior believes that attitudes and subject norms may not be sufficient to explain behavioral intentions, and that they are also affected by perceived control of behavioral performance [14]. Ajzen found that high levels of perceived behavioral control lead to stronger behavioral intentions and behavioral performance [7]. According to Dai (2021) proposed that Perceived behavioral control has a positive influence on tourists' desire to travel and tourists' travel attitudes [9]. Based on this, the following assumptions are made:

H3: Perceived behavioral control has a positive influence on tourists' desire to travel

H4: Perceived behavioral control has a positive influence on tourists' travel attitudes

\subsection{Attituade}

Theory of planned behaviour estimates that good individuals will evaluate certain behavior and has higher chance to be involved in it. Attitude towards behavior is one's positive or negative feeling when he has to perform certain actions [15]. Attitude itself has a positive relationship with behavior intention. Ajzen (1991) viewed attitude as one's degree to evaluate and assess something whether it is favorable or unfavorable[16]. According to the TPB and TRA theoretical analysis framework, behavior attitude is an effective predictor variable that drives behaviour intention, which can explain and predict behaviour intention. Which further affects the desire and travel intention. Based on this, the following assumptions are made:

H5: Attitude mediates the relationship between Subject Norm and Travel intention

H6: Attitude mediates the relationship between Perceived Behavioral Control and Travel intention

\subsection{Desire to travel}

In the MGB model, desire is considered to be the direct cause of intention, and desire is an intermediary variable. When faced with public health emergencies, people's desire to travel has a positive impact on their travel intention. Attitude, subject norms, perceived behavioral control, all affect the intention through the intermediary variable of desire[17] .Based on this, the following assumptions are made:

H7: Desire to travel mediates the relationship between Subject Norm and Travel intention

H8: Desire to travel mediates the relationship between Perceived Behavioral Control and Travel intention

\subsection{Travel intention}

Intention, defined as a plan to perform a particular behavior, is an accepted, perhaps the most important factor, for directly predicting behavior[16] . In marketing, behavioral intention, in general, is specifically a substitute indicator for actual behavior [18]. tourists tend to perform actual behaviors when their intentions to perform that behavior become stronger[19]. However, the relationship between behavior and behavioral intention is difficult to measure in reality. The assumption is that formation of behavioral intention is an immediate antecedent of behavior and represents two types of cognitions: attitude, and desire, where the weight of each predictor is in accordance with its importance perceived by an individual toward the behavior [20].

Generally, the stronger the intention to undertake the behavior, the more likely its performance becomes actuality[16]. Thus, Ajzen and Fishbein (2000) recommended that measurement of behavioral intention assumes predictive power for the future, with the focus on behavioral intention rather than actual behavior[19]. Therefore, this study uses behavioral intention as a construct for outcome, influenced by attitude, and desire H9: Desire to travel will be positively related to Travel intention H10: Attitude will be positively related to Travel intention 


\subsection{Model construction and research hypotheses \\ 2.6.1 Model construction}

Figure 1 shows the theoretical framework for this study. Subject Norm and Perceived Behavioral Control are independent variable. Travel intention is dependent variable. Attitude is mediating variable in the relationship between Subject Norm and Travel intention. Attitude is mediating variable in the relationship between Perceived Behavioral Control and Travel intention. Desire to travel is mediating variable in the relationship between Subject Norm and Travel intention. Desire to travel is mediating variable in the relationship between Perceived Behavioral Control and Travel

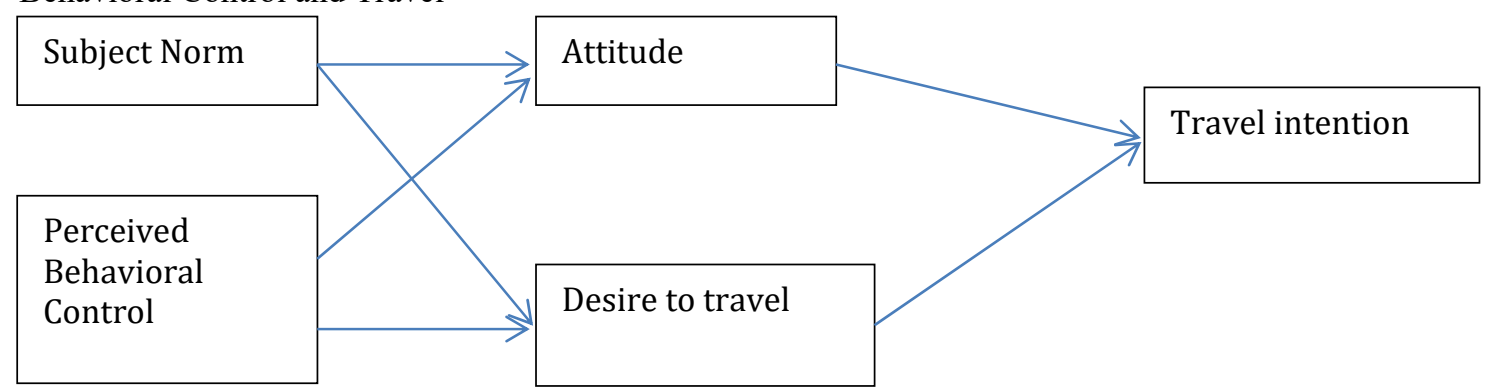

Figue 1 Research model

\section{Method}

\subsection{Sample and procedure}

The sample consisted of 437 domestic tourists to Hanoi Vietnam. One set of questionnaire were contributed during regular work hours to 742 domestic tourists. The authors directly explained the objective of this study, and explained the procedures for completing the questionnaire.

The questionnaire was developed based on a comprehensive review of the existing literature. The questionnaire was translated from English to Vietnamese and then back-translate to English by two independent bilingual scholars to ensure translation quality and guarantee equivalence of meaning.

After questionnaire was distributed, 451 complete questionnaires returned, yielding a response rate of $60.8 \%$. We were able to use responses from 437 complete and valid questionnaires for analysis.

\subsection{Measures}

\subsubsection{Subject Norm}

Subject Norm was assessed using 4 items from [9]. Items were scored on a 5-point Likert scale ranging from 1 (Strongly disagree) to 5 (Strongly agree). A sample item is "Those who are important to me are very relieved of my travel". In this study, the authors develop a confirmatory factor analysis to validate the subject norm scale (Chi-square $\chi 2(35)=3.292$; Goodness of Fit Index $[\mathrm{GFI}]=.996$; Comparative Fit Index $[\mathrm{CFI}]=.999$; Incremental Fit Index $[\mathrm{IFI}]=.999$; RMSEA=.038 ) and show that the scale is unidimensional and has high validity and reliability (Cronbach`s alpha=.934).

\subsubsection{Perceived Behavioral Control}

Perceived Behavioral Control was measured with the seven item version developed [10]. All items were measured on a five-point scale ranging from 1= "strongly disagree", to 5, "strongly agree". A sample item is "I am sure that if I want to travel, I can do it" The Cronbach's alpha coefficient was .906. A confirmatory factor analysis [21] of leader-member exchange scale yielded a good fit $(\chi 2(14)=19.353$, IFI=.993, GFI $=.985$, $\mathrm{TLI}=.988, \mathrm{CFI}=.993, \mathrm{RMSEA}=.051$ ).

\subsubsection{Attitude}

Attitude was measured with five item version developed by [10]. We used a five-point scale ranging from 1, "strongly disagree", to 5, "strongly agree". A sample item is "I think traveling abroad has a positive meaning". The Cronbach`s alpha coefficient was .864. A confirmatory factor analysis [21] of employee voice behavior scale yielded a good fit $(\chi 2(9)=1.222$, $\mathrm{IFI}=1.001, \mathrm{GFI}=.999, \mathrm{TLI}=1.002, \mathrm{CFI}=1.000, \mathrm{RMSEA}=.000)$.

\subsubsection{Desire to travel}

Desire to travel was measured with five item version developed by [9]. We used a five-point scale ranging from 1, "strongly disagree", to 5, "strongly agree". A sample item is "I want to travel recently". The Cronbach`s alpha coefficient was .864. A confirmatory factor analysis [21] of employee voice behavior scale yielded a good fit ( $\chi 2$ $(9)=.741, \mathrm{IFI}=1.000, \mathrm{GFI}=.999, \mathrm{TLI}=1.000, \mathrm{CFI}=1.000, \mathrm{RMSEA}=.000)$.

\subsubsection{Travel intention}

Travel intention was measured with 3 item version developed by [10]. We used a five-point scale ranging from 1, "strongly disagree", to 5, "strongly agree". A sample item is "I plan to travel soon". The Cronbach`s alpha coefficient was .864. A confirmatory factor analysis [21] of employee voice behavior scale yielded a good fit ( $\chi 2$ 
$(9)=17.097, \mathrm{IFI}=.993, \mathrm{GFI}=.988, \mathrm{TLI}=.988, \mathrm{CFI}=.993, \mathrm{RMSEA}=.044)$.

\subsubsection{Control variables}

We controlled age, gender and education because previous research has showed that these variables can effect on individual and organizational variables [22]

\section{Results}

\subsection{Convergent and discriminant validity}

The means, standard deviations, and zero-order Pearson correlations of all the key variables are presented in Table 1. Figure 1 showed the research model of gender, age, education, tenure, Subject Norm, Perceived Behavioral Control, Attitude, Travel intention, and Desire to travel.

As shown in Table 1, gender was negative related to Subject Norm $(\mathrm{r}=-0.56)$, Attitude $(\mathrm{r}=-0.03)$, Desire to travel $(\mathrm{r}=-0.39)$ and Travel intention $(\mathrm{r}=-0.76)$. Age, Tenure and Education was positive related to Subject Norm, Perceived Behavior Control, Attitude, Desire to travel and Travel intention.

Table 1 Descriptive statistics, correlations and scale reliabilities

\begin{tabular}{|c|c|c|c|c|c|c|c|c|c|c|c|}
\hline Variable & Mean & S.D & 1 & 2 & 3 & 4 & 5 & 6 & 7 & 8 & 9 \\
\hline 1. age & 2.39 & .907 & & & & & & & & & \\
\hline 2. Gender & 1.50 & .501 & $.137 * *$ & & & & & & & & \\
\hline 3. Tenure & 2.41 & .903 & $.863 * *$ & $.118^{*}$ & & & & & & & \\
\hline 4. Education & 2.40 & .885 & $.568 * *$ & .089 & $.524 * *$ & & & & & & \\
\hline $\begin{array}{l}\text { 5. Subject } \\
\text { Norm }\end{array}$ & 3.79 & .730 & $.263 * *$ & -.056 & $.228 * *$ & $.323 * *$ & 0.891 & & & & \\
\hline 6. Perceived & & & & & & & & & & & \\
\hline $\begin{array}{l}\text { Behavior } \\
\text { Control }\end{array}$ & 3.70 & .613 & $.379 * *$ & $.181 * *$ & $.343 * *$ & $.334 * *$ & $.264 * *$ & 0.786 & & & \\
\hline 7. Attitude & 3.68 & .671 & $.348 * *$ & -.003 & $.314 * *$ & $.387 * *$ & $.640 * *$ & $.244 * *$ & 0.947 & & \\
\hline $\begin{array}{l}\text { 8. Desire to } \\
\text { travel }\end{array}$ & 4.27 & .971 & $.232 * *$ & -.039 & $.223 * *$ & $.182 * *$ & $.248 * *$ & $.311 * *$ & $.238^{* *}$ & 0.954 & \\
\hline $\begin{array}{l}\text { 9. Travel } \\
\text { intention }\end{array}$ & 3.66 & .699 & .076 & $-.165^{* *}$ & .067 & $.118^{*}$ & $.288 * *$ & .048 & $.254 * *$ & $.185^{* *}$ & 0.862 \\
\hline
\end{tabular}

Note:

(1). Cronbach alpha reliabilities for observed variables are in parenthesis in the diagonal

(2) ${ }^{*}$ Correlation is significant at the .05 level (2-tailed)

** Correlation is significant at the 01 level (2-tailed). $N=437$

(3) The square root of AVE for discriminant validity are in parentheses along the diagonal

In order to check the fit of the five-factor model, we performed a CFA before testingthe hypothesis. The five-factor model included Subject Norm, Perceived Behavioral Control, Attitude, Desire to travel, and Travel intention. Initial questionnaire survey consisted of a total of 22 items. After analyzing EFA, set of instruments consisted of a total 19 items (because of removing SN2, ATT1, and ATT2) (see table 2). Therefore, at last the study had total 19 items (not yet including basis information items). The CFA for measure-ment model indicated the following indices: $\chi 2(144)=154.586, \mathrm{p}=.222$, GFI=.964,CFI=.998, IFI=.998, TLI=.998, RMSEA=.014 (see Figure 2). 
Table 2 Item loading of the latent constructs

\begin{tabular}{|c|c|c|c|c|c|c|c|}
\hline Item & $\begin{array}{l}\text { Subject } \\
\text { Norm }\end{array}$ & $\begin{array}{l}\text { Perceived } \\
\text { Behavioral } \\
\text { Control }\end{array}$ & Attitude & $\begin{array}{l}\text { Desire } \\
\text { travel }\end{array}$ & to & $\begin{array}{l}\text { Travel } \\
\text { intention }\end{array}$ & $\begin{array}{l}\text { Cronbach's } \\
\text { Alpha }\end{array}$ \\
\hline SN1 & .971 & & & & & & \\
\hline SN2 & .571 & & & & & & \\
\hline SN3 & .938 & & & & & & .934 \\
\hline SN4 & .977 & & & & & & \\
\hline PBC1 & & .801 & & & & & \\
\hline PBC2 & & .797 & & & & & \\
\hline PBC3 & & .835 & & & & & \\
\hline PBC4 & & .746 & & & & & .906 \\
\hline PBC5 & & .730 & & & & & \\
\hline PBC6 & & .806 & & & & & \\
\hline ATT1 & & & .545 & & & & \\
\hline ATT2 & & & .566 & & & & \\
\hline ATT3 & & & .963 & & & & .894 \\
\hline ATT4 & & & .843 & & & & \\
\hline ATT5 & & & .915 & & & & \\
\hline DTT1 & & & & .945 & & & \\
\hline DTT2 & & & & .936 & & & \\
\hline DTT3 & & & & .957 & & & .976 \\
\hline DTT4 & & & & .967 & & & \\
\hline TI1 & & & & & & .902 & \\
\hline TI2 & & & & & & .884 & .896 \\
\hline TI3 & & & & & & .813 & \\
\hline
\end{tabular}

Note: (1) Extraction Method: Principal Axis Factoring.

(2) Rotation Method: Promax with Kaiser Normalization.

The Cronbach's alphas for the extracted factors are also shown in Table 2. All alphas were above .70. All factors are reflective because their indicators are highly correlated are largely interchangeable.

Additionally, we checked the common method bias through Harman's single-factor test. The 4 items of Subject Norm, 6 items of Perceived Behavior Control, 5 items of Attitude, 5 items of Attitude, 4 items of Desire to travel and the 3 items measuring Travel intention were entered in a principal component factor analysis. The results indicated that the first factors in the model explained $33.021 \%$ of the variance. So, here, the common method bias was not issue.

Moreover, there are significant and positive correlations that exist among Subject Norm, Perceived Behavioral Control, Attitude, Desire to travel, and Travel intention. Especially, we used a series of regression to examine the direct effects that analyzed in the research. Besides, we also used a series of tests (e.g. tolerance, varianceinflation factor) to confirm the non-presence of multi-colinearity.

The second, discriminant validity refers to the degree to which items differentiate between constructs, and it is assessed by applying the following criteria: (1) The square root of the average variance extracted of each latent variable from its indicators should exceed that construct's correlation with other constructs; (2) the items should load more highly on constructs they are intended to measure than on other constructs. As shown table 3, the square root of the average variance extracted (AVE) of each latent construct is greater than that construct's correlation with other constructs. as shown in Table 2 CR were above .70, AVE were above 0.5, SQRTAVE values are greater than all Inter-Construct Correlations, discriminability is guaranteed.

Table 3. Overall reliability of the constructs and factor loadings of indicator

\begin{tabular}{lllll}
\hline & CR & AVE & MSV & Cronbach $\boldsymbol{\alpha}$ \\
\hline Attitude & 0.920 & 0.793 & 0.306 & .919 \\
PebeCo & 0.907 & 0.618 & 0.112 & .906 \\
SubjectNorm & 0.963 & 0.897 & 0.306 & .963 \\
Tralinten & 0.896 & 0.742 & 0.088 & .896 \\
Detotravel & 0.976 & 0.910 & 0.112 & .976 \\
\hline
\end{tabular}




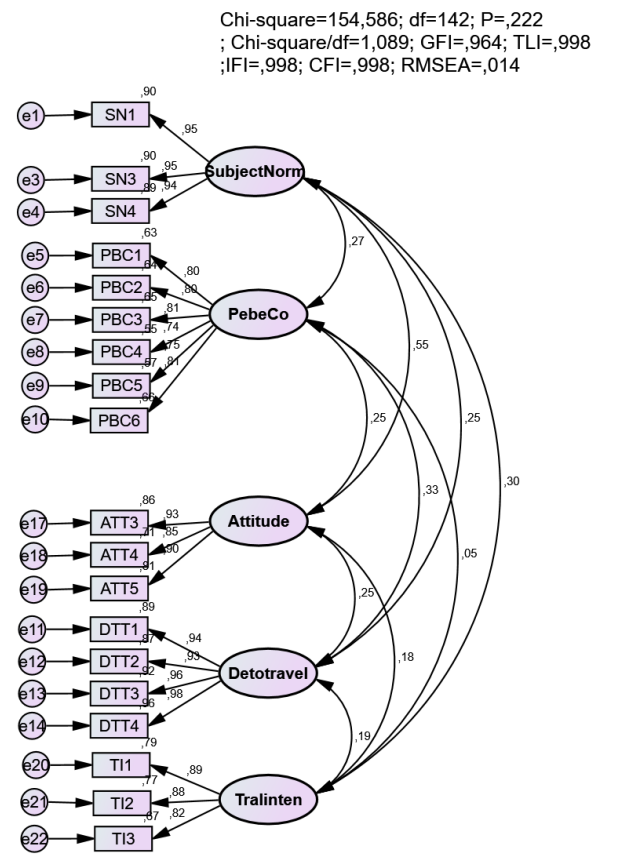

Figue 2 Confirmatory factor analysis.

\subsection{Hypothesis testing}

The authors used structural equations modeling to estimate direct and indirect effects using AMOS 22 program. This type of analysis has advantage of correcting for unreliability of measures and also provides information on the direct and indirect pathsbetween multiple constructs after controlling for potentially confounding variables. Figure 3 shows the standardized structural coefficients. The magnitude of coefficients reflectsthe relative importance of variables.

All of multi-item scales meet this criterion; each loading is significantly related toits underlying factor in support of convergent validity. The overall fit measures, multiplesquared correlation coefficients of the variables, and signs and significance levels of thepath coefficients indicate that the model fits the data well (Chisquare $=206.370 ; \mathrm{p}=.001 ;$ Chi-square $/ \mathrm{df}=1.413 ; \mathrm{IFI}=.992 ; \mathrm{GFI}=.953 ; \mathrm{TLI}=.991 ; \mathrm{CFI}=.992 ; \mathrm{RMSEA}=.031$ ).

Table 4 presents the results for the structural model in Figure.3. Structural equation modeling was performed the direct and indirect effects of the independent variables of Subject Norm, Perceived Behavioral Control, Attitude, Desire to travel and Travel intention. Indirect effects are indicated as a simple multiplicative measure of the magnitude of sequential beta weights (See Asher [3]), While total effects are calculated as the sum of direct and indirect effects (See Pedhazur [60]). Each equation or tests for multi collinearity, linearity, normality, and homoscedasticity were controlled and no problem conflicted. 


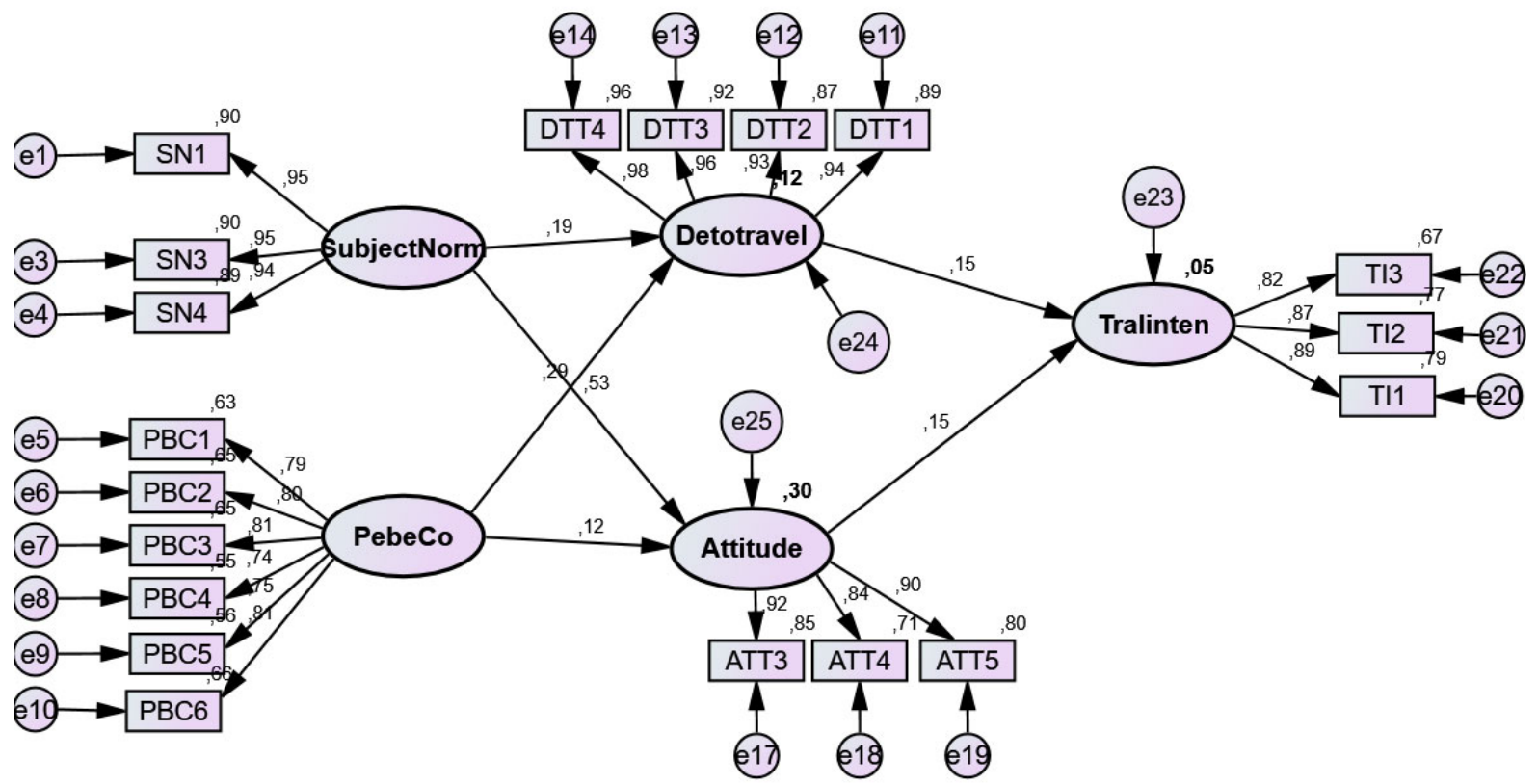

Figue 3 Results of structural equation model.

Table 4 shows that Subject Norm is closely related to and effects Attitude $(\gamma 11=.486, p<.001)$, and Desire to travel $(\gamma 21=.240, \mathrm{p}<.001)$, as predicted in hypotheses 1 and 2 , respectively. Moreover, the results show an indirect effect of Subject Norm on Travel intention $(. \beta 11=102, \mathrm{p}<.001)$ by Attitude and Desire to travel $(.156 \times .102)$. The influence of Perceived Behavior Control on Attitude is thus $.150(\mathrm{p}<.001)$ and Desire to travel is thus .511 $(\mathrm{p}<0.001)$ the results show an indirect effect of Perceived Behavior Control on Travel intention is thus $.079(\mathrm{p}<0.001)$ by Attitude and Desire to travel $(.156 \times .079)$,

Therefore, the model explains Attitude and Desire to travel well. Finally, Table 4 also presented a direct effect $(\gamma=.345, \mathrm{p}<.001)$ LMX on employee voice behavior, all supporting hypotheses 1-10.

Table 4 Structural model result (direct, indirect and total effects).

\begin{tabular}{lllll}
\hline Effect from & To & Direct effects $^{\alpha}$ & indirect effects $^{\alpha}$ & Total effects $^{\alpha}$ \\
\hline Subject Norm & Attitude & $.486^{* * *}$ & & $.486^{* * *}$ \\
Subject Norm & $\begin{array}{l}\text { Desire to travel } \\
\text { Subject Norm }\end{array}$ & $.240^{* * *}$ & & $.240^{* * *}$ \\
Perceived Behavior Control & $\begin{array}{l}\text { Travel intention } \\
\text { Attitude }\end{array}$ & $.150^{* *}$ & $.102^{* * *}$ & $.102^{* * *}$ \\
Perceived Behavior Control & $\begin{array}{l}\text { Desire to travel } \\
\text { Perceived Behavior Control }\end{array}$ & $.511^{* * *}$ & & $.150^{* *}$ \\
Travel intention & & $.079^{* * *}$ & $.511^{* * *}$ \\
Attitude & Travel intention & $.156^{* *}$ & $.079^{* * *}$ \\
Desire to travel & Travel intention & $.110^{* *}$ & $.156^{* *}$ \\
\hline Note: ${ }^{\alpha}$ Standardized Structural Coefficients: $* p<.05, * * p<.01, * * * p<.001$. & $.110^{* * *}$ \\
\hline
\end{tabular}

\section{Discussion}

Overall, the results of the study provide support for the model we proposed. Thpurpose of this study was to develop and examine a model that integrates the theories of TPB,TRA aplication for Tourism. We offer a possible explanation for the relationship between Subject Norm, Perceived Behavior and Travel intention by Attitude and Desire to travel. The current study extends existing knowledge by testing the role of Attitude and Desire to travel as mediates variable between relationship Subject Norm, Perceived Behavior and Travel intention in he transformational leadership process. We believe that this is one of the first such studies carried out in Vietnam.

Therefore, in summary, the main reasons are: 1) Differences in tourism situations. The background of the COVID-19 is different from the usual environment of tourists. The degree of binding force and pressure from the 
outside world are obviously different. 2) Differences in the concept of tourism consumers: At present, Vietnamese residents pay more and more attention to health and enjoy. In the face of the risk of epidemics, touristsmore reflect the initiative and compliance behavior, so the outside influence on the behavior of tourists is much smaller.

\section{REFERENCES}

[1] Cohen W M, Levinthal D A. Absorptive Capacity: A New Perspective on Learning and Innovation. Administrative Science Quarterly, 1990, 35(128-152

[2] Wang W, Butler J E. System deep usage in post-acceptance stage: A literature review and a new research framework. International Journal of Business Information Systems, 2006, 1(4): 439-462

[3] Hyllegard K, Ogle J, Yan R N. The impact of advertising message strategy-fair labour v. sexual appealupon Gen Y consumers' intent to patronize an apparel retailer. Journal of Fashion Marketing and Management: An International Journal, 2009

[4] Kim Y-H. An empirical examination of consumers' innovation adoption: the role of innovativeness, fashion orientation, and utilitarian and hedonic consumers' attitudes. NC Docks, 2008.

[5] Prendergast G, Tsang A S, Lo C Y. Antecedents of the intention to seek samples. European Journal of Marketing, 2008

[6] Tarkiainen A, Sundqvist S. Subjective norms, attitudes and intentions of Finnish consumers in buying organic food. British food journal, 2005

[7] Ajzen I. From intentions to actions: A theory of planned behavior. Springer, 1985.

[8] Tan G W-H, Ooi K-B, Sim J-J, et al. Determinants of mobile learning adoption: An empirical analysis. Journal of Computer Information Systems, 2012, 52(3): 82-91

[9] Dai Y, Jia L. A Study on Tourists' Travel Intention Under the Situation of Novel Coronavirus Pneumonia Epidemic. In: Proc of 6th Annual International Conference on Social Science and Contemporary Humanity Development (SSCHD 2020), 2021, 942-947

[10] Ajzen I. The theory of planned behavior. Organizational behavior and human decision processes, 1991, 50(2): 179-211

[11] Webster Jr F E. Determining the characteristics of the socially conscious consumer. Journal of consumer research, 1975, 2(3): 188-196

[12] Moutinho L. Consumer behaviour in tourism. European journal of marketing, 1987

[13] Qiu H. Developing an extended theory of planned behavior model to predict outbound tourists' civilization tourism behavioral intention. Tourism Tribune, 2017, 32(6): 75-85

[14] Fishbein M, Ajzen I. Predicting and changing behavior: The reasoned action approach. Taylor \& Francis, 2011

[15] Andriyansah D. PENGARUH INVESTASI, TENAGA KERJA DAN INDEKS PEMBANGUNAN MANUSIA TERHADAP PERTUMBUHAN EKONOMI KABUPATEN DAN KOTA DI JAWA BARAT TAHUN 2011-2015. Fakultas Ekonomi dan Bisnis Unpas Bandung, 2017.

[16] Beck L, Ajzen I. Predicting dishonest actions using the theory of planned behavior. Journal of research in personality, 1991, 25(3): 285-301

[17] Bagozzi R P. The self-regulation of attitudes, intentions, and behavior. Social psychology quarterly, 1992178-204

[18] Fredricks A J, Dossett D L. Attitude-behavior relations: A comparison of the Fishbein-Ajzen and the Bentler-Speckart models. Journal of personality and social psychology, 1983, 45(3): 501

[19] Ajzen I, Fishbein M. Attitudes and the attitude-behavior relation: Reasoned and automatic processes. European review of social psychology, 2000, 11(1): 1-33

[20] Ajzen I. Constructing a TPB questionnaire: Conceptual and methodological considerations. 2002

[21] Gowen C R, Henagan S C, McFadden K L. Knowledge management as a mediator for the efficacy of transformational leadership and quality management initiatives in U.S. health care. Health Care Management Review, 2009, 34(129-140

[22] Tangirala S, Ramanujam R. Exploring Nonlinearity In Employee Voice: The Effects of Personal Control and Organizational Identification. Academy of Management Journal, 2008, 51(6): 1189-1203 